\title{
O reflexo da inteligência coletiva nas organizações
}

\author{
Effect of collective intelligence in organizations
}

Ketry Gorete Farias dos PASSOS 1

Edna Lúcia da SILVA²

\section{Resumo}

As novas tecnologias de informação e comunicação possibilitaram o compartilhamento das informações de maneira rápida e eficaz. Da mesma forma, as organizações têm se apropriado das novas tecnologias para comunicar e disseminar informações. Este artigo tem por objetivo apresentar reflexões sobre como a Web 2.0 pode empoderar as organizações na sociedade em rede. Para isso, utilizou-se de uma revisão de literatura de caráter exploratório na qual foram abordados conceitos como inteligência coletiva, importância da sociedade em redes para as organizações, Web 2.0 e Empresa 2.0. Concluiu-se que as organizações estão se conscientizando cada vez mais do potencial da Web 2.0, não somente para divulgar produtos, mas também como um espaço para a troca de conhecimento, aprimoramento de serviços, bem como para solução de problemas. Assim as empresas que atuam em redes conseguem superar melhor suas limitações com auxílio de seus colaboradores e clientes por meio da inteligência coletiva.

Palavras-chave: Empresa 2.0. Inteligência coletiva. Sociedade em rede. Web 2.0.

\begin{abstract}
The new information and communication technologies have enabled information to be shared quickly and effectively. Similarly, organizations have adopted new technologies to communicate and disseminate information. This article therefore presents reflections on how Web 2.0 can empower organizations in the network society. To do this, concepts of collaborative networking, collective intelligence, the importance of company networks for organizations, Web 2.0 and Enterprise 2.0, were discussed. It was concluded that organizations are increasingly becoming aware of the potential of Web 2.0, not only to advertise products, but also as a space for exchange of knowledge, improvement of services and troubleshooting. Thus, companies that operate in networks can best overcome their limitations with the help of their employees and customers through collective intelligence.
\end{abstract}

Keywords: Enterprise 2.0. Collective intelligence. Network society. Web 2.0.

\section{Introdução}

A emergência da Internet a partir do final da década de 1980 e o surgimento da World Wide Web em 1994 prolongaram a precedente evolução da esfera pública, introduzindo ao mesmo tempo elementos radicalmente novos: a interconexão geral, a desintermediação e a comunicação de todos com todos (Lévy, 2005). Assim, inicia-se um novo ambiente de comunicação, no qual a virtualidade se faz presente e o tempo não é mais o fator que intervém na transferência e no compartilhamento das informações. Estamos na era da informação: a

\footnotetext{
1 Mestranda, Universidade Federal de Santa Catarina, Programa de Pós-Graduação em Ciência da Informação. Campus Universitário, Trindade, 88045-000, Florianópolis, SC, Brasil. Correspondência para/Correspondence to: K.G.F. PASSOS.E-mail: <ketry2003@gmail.com>.

2 Professora Doutora, Universidade Federal de Santa Catarina, Departamento de Ciência da Informação e do Programa de Pós-Graduação em Ciência da Informação. Florianópolis, SC, Brasil.

Recebido em 26/7/2011, reapresentado em 5/3/2012 e aceito para publicação em 30/3/2012.
} 
distância entre as pessoas não interfere mais no fluxo entre o emissor e o receptor da informação.

Este artigo tem por objetivo apresentar algumas reflexões sobre como a Web 2.0 pode empoderar as organizações na sociedade em redes. Portanto, torna-se imperativo apresentar alguns conceitos pertinentes à inteligência coletiva. Para isso, realizou-se uma pesquisa bibliográfica de caráter exploratório. A partir da revisão de literatura, constatou-se que alguns autores se popularizaram em defesa de conceitos, como o de Inteligência Coletiva (Lévy, 1996), Sociedade em Redes (Castells, 1999), Colaboração e Inteligência Coletiva (Lévy, 2005), Web 2.0 (O'Reilly, 2005) e Empresa 2.0 (Tapscoot; Williams, 2007).

No que diz respeito às mudanças na forma de comunicação, Castells (1999) acredita que estamos numa época de transição de modernos mecanismos para um novo paradigma tecnológico que se organiza em torno da tecnologia da informação. Para Castells (1999), o que caracteriza a atual revolução da informação está relacionado à aplicação da informação para a geração de conhecimentos e de dispositivos de processamento/ comunicação da informação em um ciclo de realimentação entre a inovação e seu uso. Com a mudança dos meios de comunicação, o modo de relacionamento entre os indivíduos também se modificou.

Com o advento da Internet e de outras tecnologias da informação, como a Web 2.0, tornou-se possível ter acesso a muitos dados. Algumas vezes, mais dados sobre clientes, empregados e stakeholders do que anteriormente. A princípio, as organizações ganharam mais precisão e compreensão do seu ambiente externo e interno. As recentes tecnologias, incluindo muitas das aplicações da Web 2.0, possibilitaram às organizações explorar o "coletivo" em melhor escala. De fato, o aumento do mercado de informação, as wikis, crowdsourcing ${ }^{3}$, os conceitos de sabedoria das multidões, as redes sociais, os softwares colaborativos e outras ferramentas baseadas na Web constituem o novo paradigma a partir do qual as organizações tomam decisões (Bonabeau, 2009).

Assim como nas relações sociais, a sociedade em redes e a colaboração em massa podem trazer algumas vantagens competitivas às organizações. Dessa forma, aborda-se a relação entre a sociedade em rede e a Web 2.0 como elemento potencializador da inteligência coletiva. As organizações perceberam que a colaboração pode ser uma ferramenta de geração do conhecimento e inovação no desenvolvimento de produtos (bens e/ou serviços) e também um meio de comunicação eficaz e eficiente com clientes e parceiros.

Por isso, quando se aborda o papel da sociedade em redes para as organizações, parte-se do princípio de que, com o advento das novas tecnologias da Web 2.0, tornou-se possível para muitas organizações de todo o mundo conhecer melhor os fatores que permeiam seu ambiente externo e interno. As ferramentas da Web 2.0 possibilitaram a geração de forma contínua e adaptável a novas situações do ambiente organizacional; portanto, se bem utilizadas, podem contribuir para destacar as organizações no mercado cada vez mais competitivo.

De acordo com Lévy (1996), quando refletimos no potencial que a Web 2.0 pode proporcionar às organizações, estamos pensando no poder da inteligência coletiva. O conceito de inteligência coletiva pode ser definido como um tipo de inteligência que é disseminado em grande escala e em tempo real no ciberespaço.

Em relação a isso, Lévy (2005), de-fende que um dos aspectos mais transformadores da globalização foi a informatização e a consequente geração da sociedade em rede. Para Lévy (2005), o ciberespaço é muito mais inclusivo do que todos os outros meios de comunicação anteriores, pois ele permite a expressão pública a todos os indivíduos, grupos, instituições e comunidades. Desse modo, as mídias não se ligam mais a um público localizado, mas a uma comunidade virtual distribuída por toda a parte num mundo de ouvintes, expectadores, leitores e contribuintes.

Analogamente, devido à competitividade e crescente mudança no modo de desenvolver produtos, sejam eles bens ou serviços, imperou-se aos gestores a constante preocupação com atualização e qualidade no desenvolvimento de produtos. Nesse contexto, visto que o ciberespaço possibilita a junção de inteligências coletivas em escalas globais e em tempo real, por que as organizações não podem se aproveitar do potencial da inteli-

\footnotetext{
3 Modelo de produção que utiliza a inteligência e os conhecimentos coletivos de voluntários da Internet para resolver problemas, criar conteúdos ou desenvolver novas tecnologias (Tapscoot; Williams, 2007).
}

TransInformação, Campinas, 24(2):127-136, maio/ago., 2012 
gência coletiva para criar soluções corporativas? Organizações do mundo todo, conscientes do potencial das novas tecnologias da informação, estão buscando cada vez mais ideias que impulsionem o mercado, conectando-se e utilizando-se de ferramentas da Web 2.0. Lévy (1996) acredita que na sociedade atual, quanto mais se é virtual, mais se faz dinheiro, quanto mais se penetra no mundo das ideias, mais se é recompensado pelo mercado. Esse potencial está cada vez mais sendo explorado pelas organizações por meio das redes sociais da Internet, como, por exemplo, Orkut, Facebook, Twitter, Myspace, Ning, entre outros.

As organizações se deram conta de que, além de ser um meio de comunicação mais econômico e acessível do que os convencionais, a Internet fornece uma variedade de ferramentas, o que possibilitou sanar muitas dúvidas em tempo hábil em relação à percepção do cliente a um determinado produto ou empresa. Também se tornou possível, por intermédio das ferramentas da Web 2.0, capturar críticas e/ou sugestões em tempo real sobre o lançamento de produtos ou tendências do mercado. Atualmente, com a Internet, é possível perguntar aos clientes quais são suas expectativas em relação a novos produtos (bens ou serviços), avaliar de forma rápida e com custos quase nulos seu processo produtivo e/ou de prestação de serviços, classificar e encontrar demandas de perfis de usuários através da Web social (Orkut, Twitter, Facebook, Ning, entre outros), descobrir a personalidade e as preferências de determinados clientes, entre outras opções.

Portanto, neste artigo, parte-se do pressuposto de que a Web 2.0 e a inteligência coletiva podem potencializar as organizações. Para isso, apresentam-se conceitos de comunidade virtual, sociedade em rede e de inteligência coletiva, que são fundamentais para a compreensão dos aspectos que envolvem o conceito de Web 2.0.

\section{A colaboração e a inteligência coletiva}

Lévy (2005) explica que a Internet criou um novo tipo de comunidade, uma comunidade que não é igual à tradicional. Para compreender como as organizações podem se beneficiar do potencial da inteligência coletiva, é necessário anteriormente explicar o conceito de comu- nidade virtual. Na visão do autor, as mudanças provocadas pela globalização e pelas novas tecnologias, além da desterritorialização da esfera pública, deixaram antever a ascensão de comunidades desvinculadas dos territórios físicos. Como consequência, as mídias não se ligam mais a um público localizado, mas a uma comunidade virtual distribuída por toda parte num mundo de ouvintes, espectadores, leitores e contribuintes. Para Lévy (2005), as economias virtuais se constituíram de maneira original no ciberespaço, a partir da vontade de comunicação em torno de pontos comuns entre os internautas. O tamanho dessas comunidades envolve questões comerciais, culturais e políticas maiores, na medida em que representam ao mesmo tempo um mercado, uma fração da opinião no novo espaço público e uma potência da inteligência coletiva (coordenação, cooperação, troca de saberes, ajuda mútua).

A transformação da sociedade tradicional para a sociedade virtual está centrada no fato de que, atualmente, com o advento das novas tecnologias de informação, nos tornamos produtores, coprodutores, disseminadores e canais de informação ao mesmo tempo. As tecnologias da Web 2.0 possibilitaram aos indivíduos a fácil navegação, criação e edição de conteúdos. Desse modo, por exemplo, não precisamos mais contatar uma emissora de televisão para produzir um documentário, basta apenas filmar com uma simples câmera amadora e enviar o conteúdo ao Youtube e em questão de segundos algumas centenas ou milhares de pessoas podem assistir à produção, sem custos e muito menos intermediários.

Em relação a isso, dois conceitos pertinentes à colaboração na sociedade em redes podem exemplificar o poder das novas tecnologias de informação e comunicação para a inteligência coletiva: Crowdsourcing e Peering. Para Tapscoot e Williams (2007), o Crowdsourcing consiste no modelo de produção que utiliza a inteligência e os conhecimentos coletivos de voluntários espalhados pela Internet para resolver problemas, criar conteúdos ou desenvolver novas tecnologias. E Peering é uma forma de produzir produtos que dependem totalmente de comunidades auto-organizadas e igualitárias de indivíduos que se unem voluntariamente para produzir um resultado compartilhado. O Peering utiliza as motivações voluntárias de maneira a ajudar a destinar à pessoa certa a tarefa 
certa com mais eficácia do que empresas tradicionais. $\bigcirc$ motivo é a autosseleção. Ao voluntariamente se selecionarem para tarefas criativas e com uso intensivo de conhecimento, as pessoas estão distintamente capacitadas.

O exemplo mais popular de Peering é o sistema operacional Linux. Em 1991, Linus Torvalds criou uma versão simples do sistema operacional Unix. A partir das colaborações de outros programadores, Linus decidiu licenciar o sistema operacional sob uma Licença Pública Geral (GPL) para que qualquer pessoa pudesse usá-lo gratuitamente, contanto que disponibilizasse para os outros as mudanças feitas no programa. Por ser confiável e gratuito, tornou-se um sistema operacional útil para computadores que abrigavam servidores da Web e banco de dados. Muitas empresas consideram o Linux uma pedra fundamental dos softwares empresariais. Apesar de poder ser usado livremente, o Linux tem sido incorporado em todos os tipos de produtos lucrativos desenvolvidos por grandes empresas, como BMW, IBM, Motorola, Philips e Sony. A nova promessa de colaboração é que com o Peering, pode-se explorar a capacidade, a engenhosidade e a inteligência humana com mais eficiência e eficácia. Essa promessa substituirá as hierarquias empresariais tradicionais como mecanismo essencial para a criação de riqueza na economia (Tapscoot; Williams, 2007).

\section{O papel da sociedade em redes para as organizações}

Castells (1999) entende que a cultura da virtualidade associada às novas tecnologias de informação e comunicação contribui para a transformação do tempo em nossa sociedade de duas formas: na simultaneidade e na intemporalidade. Atualmente, a virtualidade possibilita a comunicação entre as pessoas em tempo real, reunindo indivíduos com os mesmos interesses em conversas interativas, oferecendo instantaneidade, que vem conquistando barreiras temporais. A simultaneidade e a intemporalidade possibilitaram à sociedade organizar-se em torno de redes de comunicação na Internet. As redes possibilitaram aos indivíduos compartilhar informações e desenvolver soluções em colaboração, independentemente do local e até mesmo do tempo. Um exemplo dessa afirmação são os grupos de discussões abertos que recebem diariamente contribuições de milhares de internautas dispostos a ajudar sem receber necessariamente nada em troca, a não ser pelo status de pró-atividade e pelo sentimento de colaboração.

Um aspecto importante a ser esclarecido é o papel das redes para as organizações. Na compreensão de Castells (1999), a rede é constituída por nós e conexões dois a dois, que podem interligar-se direta ou indiretamente. Assim, a Internet como novo meio de comunicação rompe com a clássica distribuição hierárquica entre emissores e receptores ao possibilitar que cada nó possa produzir e distribuir mensagens simultaneamente. Além disso, a rede é composta por uma estrutura aberta capaz de expandir-se de forma ilimitada, integrando novos nós desde que consigam comunicar-se internamente, o que faz com que o processo de comunicação seja expandido de maneira exponencial. Nesse contexto, Castells (1999) afirma que uma sociedade baseada em redes pode constituir-se num sistema aberto altamente dinâmico e suscetível à inovação sem ameaças ao seu equilíbrio.

Um exemplo do potencial da sociedade em redes é o grupo de discussão TakinglTGlobal: 110 mil membros registrados em quase 200 países se reúnem com líderes empresariais e governamentais no Fórum Econômico Mundial. O site lista mais de 2 mil projetos comunitários iniciados/administrados por jovens (entre 13 e 24 anos) que enfrentam questões desde a eliminação do hiato digital nas áreas rurais da Índia à prevenção do HIV em Uganda. Essas novas colaborações atenderão não apenas a interesses comerciais, mas também ajudarão as pessoas a executarem tarefas como espírito público, desde curar doenças genéticas, prever mudanças climáticas globais e encontrar novos planetas e astros (Tapscoot; Williams, 2007).

Dessa forma, podemos observar que a união da sociedade em redes é um grande passo para a solução de grandes problemas sociais que podem ser resolvidos por meio do compartilhamento de ideias e da inteligência coletiva. Portanto, já que os problemas são da sociedade, por que não deixar que ela possa refletir e encontrar soluções em conjunto, numa junção de redes de pensamentos para solucionar seus próprios problemas? 
A esse respeito, Castells (1999) defende que as redes são os instrumentos mais apropriados para a economia capitalista baseada na inovação, globalização e concentração descentralizada. As redes podem beneficiar o trabalho, os trabalhadores e as empresas voltadas para a flexibilidade e a adaptabilidade, bem como para uma cultura de desconstrução e reconstrução contínuas. Portanto, a tendência é que certas organizações desenvolvam produtos e gerem soluções de problemas por meio da colaboração e da exploração do potencial da inteligência coletiva. Para Castells (1999), nem sempre a solução está dentro das organizações, às vezes, é necessário olhar para fora, encontrar outros pontos de vista.

Castells (1999) sustenta a ideia de que as redes são a nova morfologia social da coletividade. A utilização em grande escala das redes pode modificar os resultados de processos produtivos, de experiências, de poder e de cultura. A presença ou a ausência na rede são fontes cruciais de dominação e transformação de nossa sociedade: uma sociedade que, portanto, pode-se denominar de sociedade em rede, caracterizada pela primazia da morfologia social sobre a ação social.

Portanto, o novo modo de se comunicar criado pela sociedade transpôs barreiras temporais e geográficas. Atualmente o poder das redes de comunicação faz com que pessoas de diversas partes do mundo se comuniquem com milhares de outras, utilizando apenas um computador e a Internet. Por trás do poder que as redes de comunicação vêm proporcionando, está o poder da inteligência coletiva.

Dispor da colaboração para discussão e apreciação dos fatos na Web tornou-se tarefa cotidiana da sociedade em redes, mas esse conjunto de ideias, a mistura do pensamento de diferentes mentes, várias opiniões e diversos pontos de vista não gerariam contradições? Para Lévy (1996), pelo contrário, a sociedade humana atravessou uma barreira de interconexão sem precedentes na história, visto que atingiu o estágio em que ela passa a dispor de uma memória. A sociedade inventou a si mesma como coletivo capaz de aprender em longo prazo, independente da morte dos indivíduos. Por isso, a inteligência é concebida como o conjunto de aptidões cognitivas de saber, de perceber, de lembrar, de aprender, de imaginar e de raciocinar. Na medida em que os indivíduos possuem essas aptidões, podem ser considerados inteligentes.

\section{Inteligência coletiva}

131

A inteligência coletiva pode ser definida como uma inteligência distribuída em toda parte, continuamente valorizada e cooperada em tempo real. Emergente de processos cooperativos competitivos, a inteligência coletiva se baseia essencialmente na cooperação de agentes concorrentes. Logo, quanto mais se avança na cooperação, mais se abre o leque das formas de competição. Em contrapartida, a cooperação leva à concorrência e à cooperação no interior de um elo autocriador que engloba uma realidade cada vez mais vasta, diversa e integrada, que é o movimento em si da inteligência coletiva (Lévy, 1996).

Johnson (2003) explica que quando apenas poucos cérebros exploram determinado problema, as células permanecem desconectadas, cada uma seguindo um curso aleatório. No entanto, quando conectados a um maior número de mentes, há uma aglutinação e um novo modo de ver o mundo, compartilhado por milhares de indivíduos. Para Johnson (2003) está havendo uma mudança de pensamento dos indivíduos, estamos mudando regras de pensamento do nível top-down para bottomup: não agimos mais a partir de ideias de um líder, as decisões não estão somente sendo tomadas pela alta administração. Existe um imenso potencial para geração de ideias e os gestores devem aproveitar o potencial de todos os membros da organização para fazer uso das ideias coletivas. Atualmente, atos locais geram ações coletivas que podem produzir um comportamento global; como na colônia de formigas, o cérebro da colônia nada mais é do que a soma de milhares e milhares de decisões sendo executadas individualmente. Logo, as formas de comportamento emergentes ficam mais inteligentes com o tempo e reagem melhor às necessidades específicas e mutantes de seu ambiente. Essa nova maneira de pensar é o potencial que a inteligência coletiva possibilita à sociedade conectada.

Esse potencial de exploração da inteligência coletiva pode ser exemplificado no caso da Goldcorp. A empresa, em 1999, era uma pequena firma de mineração de ouro, com sede em Toronto, que estava lutando para sobreviver, sitiada por greves, dívidas e um custo de produção excessivamente alto. McEwen, diretor geral, após assistir a uma conferência do Massachusetts Institute of 
Technology (MIT) para jovens presidentes, achou que talvez a solução de seus problemas fosse abrir o processo de exploração da mesma maneira que Torvalds "abriu o código" do Linux. Em março de 2000, o "Desafio Goldcorp" foi lançado com um prêmio de US\$575 mil em dinheiro para os participantes que tivessem os melhores métodos e estimativas. O objetivo do concurso era encontrar 170 toneladas de ouro. Dessa forma, a ajuda veio tanto de geólogos como de alunos de pós-graduação, consultores, matemáticos, químicos, entre outros. A empresa recebia dos inscritos diversas informações que apresentavam matemática aplicada, física avançada, sistemas inteligentes, computação gráfica e soluções orgânicas para problemas inorgânicos. Mais de $80 \%$ dos novos alvos produziram quantidades significativas de ouro. Desde o início do desafio, surpreendentes 230 toneladas de ouro foram encontradas. McEwen estima que o processo colaborativo reduziu dois ou três anos do tempo de exploração. Portanto, a inteligência coletiva pode solucionar problemas de distintas formas (Tapscoot; Williams, 2007).

A partir do conhecimento dos conceitos da sociedade em rede e da inteligência coletiva e do seu potencial para a sociedade em geral bem como para as organizações, pode-se identificar os componentes envolvidos nesse processo de comunicação. Atualmente, com o advento das novas tecnologias de informação e comunicação, criou-se uma variedade de ferramentas na Internet com o intuito de facilitar a comunicação no ciberespaço.

Com o desenvolvimento de softwares para o compartilhamento de informações, o termo Web 2.0 foi usado para tentar diferenciar essa nova abordagem de compartilhamento de informação e conhecimento.

\section{A Web 2.0}

A Web 2.0 não se refere apenas à atualização da Web tradicional, mas a uma mudança na forma como ela é encarada por usuários e desenvolvedores, ou seja, o ambiente de interação que engloba inúmeras linguagens e motivações. O conceito "Web 2.0" foi criado numa conferência de brainstorming entre a O'Reilly e a MediaLive International em 2004 (O'Reilly, 2005). A Web 2.0 ou Web social representa um novo padrão de interação: viabiliza e estimula a colaboração, a interação "muitos-muitos"e a horizontalização da comunicação (Cavalcanti; Nepomuceno, 2007; Antoun, 2008; Primo, 2008; Galdo, 2010).

O sucesso da Web 2.0 está baseado no fato de que se soube aproveitar o poder da inteligência coletiva. Desse modo, à medida que os usuários adicionam conteúdo e novas páginas da Web, eles passam a integrar a estrutura da rede enquanto outros usuários descobrem o conteúdo e se conectam a ele. Do mesmo modo que se formam sinapses no cérebro - com as associações fortalecendo-se em função da repetição ou da intensidade -, a rede de conexões cresce organicamente como resultado da atividade coletiva de todos os usuários da rede (O'Reilly, 2005).

As informações obtidas por meio da Web 2.0, além de estratégicas e valiosas para as organizações, podem ser obtidas de forma rápida, segura e mais econômica se comparada aos meios tradicionais de pesquisas. Muitas das tecnologias da Web 2.0, principalmente as redes sociais, informam os perfis dos clientes. Comunidades de redes sociais como o Orkut podem informar o tipo de atividade do cliente, residência, profissão, livros preferidos, atividades de lazer etc. O Facebooké um exemplo clássico de como as empresas podem captar recursos com as ações dos próprios clientes; nele, muitas empresas fazem divulgação de seus produtos e o cliente tem a opção de escolher as propagandas que deseja visualizar.

O diferencial das tecnologias da Web 2.0 e da Web 1.0 é que com as ferramentas da Web 2.0 os indivíduos são consumidores e produtores ao mesmo tempo. Atualmente, muitas ferramentas da Web 2.0 facilitam a criação do conhecimento no ciberespaço. Um exemplo de como os próprios usuários podem classificar suas informações na Internet são os sistemas de bookmarks como, por exemplo, o Del.ici.ous e outros como o Flickr. Nessas ferramentas, é possível adicionar etiquetas (tags) e criar suas próprias palavras-chave. Outras tecnologias que reúnem o conceito de blog e diferentes formas de interação de usuários, além de facilitarem a troca de informações, estão se tornando muito populares nos últimos anos, entre elas podemos citar o Flickr e o Twitter. O Flickr diferencia-se dos fotologs principalmente pela possibilidade de organização das fotos através de tags e por disponibilizar opções como inserção de observações dentro da foto, acrescentando informações essenciais para compreensão do contexto no qual a imagem foi retirada (Aquino, 2007). 
Autores como Tapscott e Williams (2007) defendem que em vez de se ler um livro é possível escrever um. A Wikipédia é um exemplo do potencial da inteligência coletiva para nossa sociedade. Trata-se de uma enciclopédia criada de maneira colaborativa, escrita por dezenas de milhares de colaboradores, com cinco funcionários em tempo integral. A Wikipédia é dez vezes maior que a enciclopédia britânica e tem aproximadamente a mesma precisão, apesar dos riscos inerentes a uma enciclopédia aberta na qual é possível que qualquer pessoa acrescente suas próprias opiniões. A Wikipédia continua a crescer rapidamente em amplitude, qualidade e tráfego, baseando-se na premissa de que a colaboração entre usuários melhorará o conteúdo ao longo do tempo, da mesma maneira que a comunidade de código aberto aperfeiçoou a primeira versão do Linux.

A Wikipédia é o exemplo mais claro do sucesso da colaboração na sociedade em redes. Ela faz tanto sucesso que existem derivações como wikilivros (manuais de textos livres), wikiversidade (cursos online livres), wikicionário (dicionário livre), wikiquote (coleção de citações), entre outros. Muitas organizações atentas ao potencial que essa tecnologia oferece estão desenvolvendo programas de incentivo aos funcionários que utilizam wikis corporativas para o desenvolvimento da gestão do conhecimento. As wikis também podem ser utilizadas para descrição de tarefas complexas de trabalho e registros de eventuais problemas, servindo não apenas como um manual de procedimentos de tarefas, mas também como fonte de informação para as organizações e para futuros membros.

Hoje o fenômeno dos blogs aponta para mudanças mais profundas que a nova Web causará na economia. Segundo Tapscott e Williams (2007) os blogs foram descritos como a maior "cafeteria do mundo". Eles traçam a cada momento um retrato dos pensamentos e sentimentos das pessoas a respeito do que está acontecendo agora, fazendo com que a Web deixe de ser uma coleção de documentos estáticos e passe a ser uma conversa em andamento. Os anunciantes já entenderam isso e criaram os seus próprios blogs para conversar com clientes interessados em seus produtos. As empresas usam blogs como grupos de discussão regularmente, prestando atenção no que as pessoas estão dizendo a respeito de sua própria imagem ou dos seus produtos.
O blog, além de ser um meio de comunicação com baixo custo e de simples utilização, necessita de cuidados com sua manutenção, pois não basta apenas criá-los e deixá-los circulando livremente na Web. É necessária a constante atualização de informações e constante comunicação com os clientes. Não se trata de uma tarefa muito simples, uma vez que clientes insatisfeitos requerem respostas e esclarecimentos sobre determinados problemas em tempo hábil, porém trata-se de uma nova maneira de se comunicar com os atuais clientes e um espaço para conquistar clientes em potencial. Um exemplo de sucesso com a utilização da ferramenta blog é a empresa Claro. O blog da Claro (http://www. claroblog.com.br/) não serve apenas como meio de divulgação dos produtos da empresa, sua principal função é manter o relacionamento com seus clientes. Para isso, o blog da Claro mantém enquetes, promoções, informa os clientes sobre novidades de produtos, bem como constitui-se um canal para sugestões e reclamações.

A partir do conhecimento do potencial que as ferramentas da Web 2.0 podem proporcionar às organizações, cunhou-se o termo Empresa 2.0. Para Schneckenberg (2009), ferramentas da Web 2.0, como plataformas corporativas, possuem o potencial de melhorar o desempenho corporativo ainda que em longo prazo, desde que sejam adotadas como tecnologias de informação pelos funcionários para criar com os pares ambientes de aprendizagem que motivem interações e decisões em suas áreas específicas de interesse.

\section{Empresa 2.0}

McAfee (2006) cunhou o termo Enterprise 2.0 (Empresa 2.0) para representar as tecnologias da Internet e as práticas empresariais que permitem que colaboradores em contextos ricos em informação empresarial produzam e troquem conhecimento em colaboração e interação.

As novas tecnologias da Web 2.0 garantem às organizações um bom entendimento de eventos e tendências do ambiente externo, interno e no processo de tomada de decisão. As informações advindas das ferramentas da Web 2.0, se bem fundamentadas, podem gerar informações e análises de forma contínua e adaptável às novas situações no ambiente organizacional. 
Tapscott e Williams (2007) acreditam que empresas inteligentes estão estimulando, em vez de combater, o crescimento vertiginoso de enormes comunidades online - muitas das quais surgiram na periferia da Web, atraindo dezenas de milhões de participantes da noite para o dia. Com um número maior de empresas descobrindo os benefícios da colaboração em massa, esse novo modo de organização substituirá estruturas empresariais tradicionais como o motor primário de criação de riqueza na economia.

A empresa Fiat pode ilustrar adequadamente como as organizações podem se utilizar da Web 2.0 para potencializar seu processo produtivo. A Fiat desenvolveu o novo carro Uno pelas sugestões de clientes e internautas por intermédio do Formspring. A empresa alocou uma equipe para responder a usuários - predominantemente pertencentes ao público jovem - e captar deles informações e sugestões. Os internautas responderam a cerca de 50 questões relacionadas às características desejadas no novo carro da Fiat, e o resultado foi o novo Uno, desenvolvido pelas sugestões e ideias dos internautas.

A construtora Tecnisa é outro modelo de como as organizações podem se beneficiar das novas tecnologias da Web 2.0. Aproveitando a oportunidade de se envolver com os clientes, a construtora criou um apartamento virtual decorado em 3D, semelhante ao apartamento real, e convida os internautas a visitar seu espaço no jogo Second Life. O Second Life é um software que simula os aspectos da vida real e social do ser humano. Dessa forma, os clientes conseguem visualizar o produto antes mesmo de comprá-lo. Isto possibilita que empresas de qualquer parte do mundo divulguem seus produtos de forma rápida e econômica.

Para Bonabeau (2009), se o objetivo é gerar soluções e/ou avaliações de produtos, as organizações devem considerar três tipos de abordagens gerais no uso da Web 2.0: solidariedade, agregação aditiva e auto-organização. Esses fatores têm prós e contras e muitas aplicações têm combinado essas diferentes abordagens.

A primeira abordagem - a solidariedade-consiste em coletar ideias para gerar ou avaliar uma solução. Dessa forma, as organizações podem explorar o conhecimento de pessoas ou grupos que não fazem parte do seu quadro funcional, podendo obter ajuda de atores externos. A solidariedade dos usuários da Web 2.0 amplia o número de indivíduos que estão gerando e/ou avaliando soluções.
O desenvolvimento de softwares open-source (código aberto) é o exemplo clássico do poder da coletividade. Um número elevado de pessoas trabalhando com objetivos comuns num projeto pode solucionar e descobrir cada erro existente. A filosofia subjacente é que existem muitas pessoas de fora que podem ajudar, além disso, esses indivíduos não estão necessariamente onde se espera que eles estejam. Já a segunda abordagem envolve a agregação aditiva: as empresas podem coletar informações numa miríade de recursos e realizar uma inferência através delas. O processo pode ser usado para agregar dados de grupos tradicionais de decisão ou tais dados podem ser combinados com a solidariedade, incluindo informações de um conjunto mais amplo de pessoas. A auto-organização possui relação com mecanismos de interação entre membros de grupos que podem potencializar os resultados. Exemplos de uso construtivo de auto-organização que interagem na agregação de valor incluem a Wikipedia e a Intellipedia (a versão da CIA da Wikipedia para comunidades inteligentes) e o Digg. Tais aplicações permitem que as pessoas criem valor por adicionar ou apagar contribuições de outros participantes. Mas existe um risco: se os mecanismos de interação não forem projetados corretamente, o todo pode acabar por ser menor que a soma das partes (Bonabeau, 2009).

A Amazon pode também ser citada como modelo de sucesso. A empresa desenvolveu uma ciência sobre o envolvimento dos usuários. Ela os convida e os incentiva a participar de avaliações de seus produtos, usa a atividade deles para produzir melhores resultados de busca, incentiva a criação de resenhas dos livros. Enquanto uma busca da BarnesandNoble.com vai provavelmente levar a resultados encabeçados pelos produtos da própria companhia ou que sejam patrocinados, os da Amazon sempre apresentam em primeiro lugar os "mais populares", uma computação em tempo real baseada não apenas em vendas, mas em outros fatores que os conhecedores da Amazon chamam de "fluxo" em torno dos produtos. Contando com a participação do usuário em escala muitíssimo maior, não surpreende que as vendas da Amazon excedam à concorrência (O'Reilly, 2005).

Muitos dos problemas enfrentados pelas organizações podem ter solução através de atores externos, que estão muito além dos lugares tradicionais que os gestores podem encontrar fora das organizações. Na verdade, todo sucesso como a Wikipédia pode ser olhado 
em sua superfície simples, que desmente os complexos mecanismos para o aproveitamento da inteligência coletiva.

Bonabeau (2009) acredita que existe um conjunto de motivações que levam as pessoas a participarem do compromisso coletivo. Incentivos monetários, prêmios e outras promoções podem ser efetivamente estimulantes para participar nas atividades, como, por exemplo, para predições de mercado. Todavia, muitas recompensas explícitas parecem ser importantes, isso significa que as pessoas não procuram ajudar apenas por dinheiro, mas ajudar outras pessoas e colaborar para o desenvolvimento do conhecimento humano parece ser importante para os internautas. Um exemplo de movimento de open-source, a Wikipédia e outros similares esforços têm mostrado a participação nas comunidades, o desejo de transferir o conhecimento ou compartilhar experiências e o senso de cidadania como sendo fortes motivadores.

\section{Considerações Finais}

As novas tecnologias da Web 2.0 possibilitaram a colaboração e o compartilhamento das informações ganhando cada vez mais importância para as organizações visto que por meio destas é possível trocar ideias e experiências, promovendo um ambiente de criatividade, inovação e aprendizagem organizacional.

A busca cada vez maior pelo diferencial competitivo e a nova lógica da economia forçam as organizações a gerar mais soluções e produtos cada vez mais inovadores. Como essa tarefa se torna cada vez mais difícil, nem sempre todas as respostas estão dentro das organizações. Os gerentes devem estar atentos ao poder de comunicação e captação de ideias que as redes sociais e os aplicativos da Internet podem proporcionar. A principal vantagem é que essas informações podem ser capturadas em tempo real e a um custo muito baixo.

Deste modo, é a competição que torna as empresas mais inteligentes, o que faz com que utilizem todos os recursos do trabalho cooperativo em rede, da engenha- ria simultânea, da Intranet e da Internet, capitalizando a memória da empresa e suas competências, fazendo com que vendam e consumam cada vez mais informações e conhecimentos.

A atual sociedade em redes é tão complexa que nenhuma empresa pode desenvolver inovações necessárias para competir na indústria da tecnologia da informação ou em qualquer outro ramo. As empresas inteligentes devem saber explorar toda inovação gerada utilizando-se da inteligência coletiva e da colaboração para o desenvolvimento de soluções. Portanto, a Web 2.0 envolve um número de pessoas muito maior do que as organizações jamais poderiam alocar internamente.

Por conseguinte, a Web 2.0 pode auxiliar as organizações a se tornarem mais inteligentes não apenas compartilhando informações, mas também pela possibilidade da criação e da edição do conhecimento na Web. A Web 2.0 ficou popular pela sua fácil utilização e pela sua atemporalidade, registrando a memória da humanidade. É também popular pela possibilidade de acessar as informações nas nuvens, ou seja, não exige que nenhum software seja instalado e pode ser acessada em qualquer dispositivo que tenha acesso à Internet. Outra facilidade é que as ferramentas da Web 2.0 são compatíveis com diversos dispositivos móveis, como celulares, iphone, ipad, entre outros. Essa mobilidade aumenta ainda mais a frequência de uso e a oportunidade de colaboração.

Da mesma forma que a sociedade em redes, as comunidades virtuais e os fóruns de discussão servem de espaço para o compartilhamento do conhecimento entre os indivíduos. As organizações estão se conscientizando do potencial das novas tecnologias da Web 2.0, não somente como um novo espaço de divulgação de produtos, mas também como um espaço para a troca de conhecimento, desenvolvimento de serviços, bem como para a solução de problemas. Assim, as empresas podem ser tornar mais competitivas, explorando o potencial da inteligência coletiva e fazendo com que seus resultados sejam maiores do que a soma das partes.

\section{Referências}

ANTOUN, H. As transformações na sociedade hiperconectada. In: ANTOUN, H. Web 2.0: participação e vigilância na era da comunicação distribuída. Rio de Janeiro: Mauad, 2008. p.11-27.
AQUINO, M.C. O hipertexto como potencializador da memória coletiva: um estudo dos links na web 2.0. 2007. Dissertação (Mestrado em Comunicação e Informação) - Programa de 
Pós-Graduação em Comunicação e Informação, Universidade Federal do Rio Grandes do Sul, Porto Alegre, 2007.

BONABEAU, E. Decisions 2.0: the power of collective intelligence. MIT Sloan Management Review, v.50, n.2, p.44-53, 2009.

CASTELLS, M. A sociedade em rede. São Paulo: Paz e Terra, 1999.

CAVALCANTI, M.; NEPOMUCENO, C. O conhecimento em rede. Rio de Janeiro: Elsevier, 2007.

GALDO, A.M.R. Web 2.0 e colaboração científica: análise do uso científico-acadêmico por docentes de pós-graduação stricto sensu em ciência da informação no Brasil. 2010. Mestrado (Ciência da Informação) - Programa de Pós-Graduação em Ciência da Informação, Universidade Federal de Santa Catarina, Florianópolis, 2010.

JOHNSON, S. Emergência: a dinâmica da rede em formigas, cérebros, cidades e softwares. Rio de Janeiro: Zahar, 2003.
LÉVY, P. O que é o virtual?. São Paulo: Editora 34, 1996.

LÉVY, P. Pela ciberdemocracia. In: MORAES, D. (Org.). Por uma outra comunicação: mídia, mundialização cultural e poder. Niterói: Record, 2005. p.367-384.

MCAFEE, A. Enterprise 2.0: the dawn of emergent collaboration. MIT Sloan Management Review, v.47, n.3, p.9-21, 2006.

O'REILLY, T. What is web 2.0: design patterns and business models for the next generation of software. 2005. Available from: <http://www.oreillynet.com/pub/a/oreilly/tim/news/ 2005/09/30/what-is-Web-20.html>. Cited: 5 May 2008.

PRIMO, A. Interação mediada por computador. Porto Alegre: Sulina, 2008.

SCHNECKENBERG, D. Web 2.0 and the empowerment of the knowledge worker. Journal of Knowledge Management, v.13, n.6, p.509-520, 2009.

TAPSCOT, D.; WILLIAMS, A.D. Wikinomics: como a colaboração em massa pode mudar o seu negócio. Rio de Janeiro: Nova Fronteira, 2007. 